\title{
ÉTICA E INTEGRIDADE: CONDUTAS PARA PRODUÇÕES CIENTÍFICAS NO BRASIL
}

\author{
Fabiana Divina da Silva', Ivânia Vera², Roberta Almeida Elias ${ }^{3}$, Roselma Lucchese $^{4}$, \\ Sara da Costa Fernandes ${ }^{5}$, Sulamita da Silva Lucas $^{6}$
}

Objetivo: apresentar uma análise de dispositivos legais, que sejam norteadores de pesquisas científicas no Brasil quanto à ética, integridade e seus aspectos, em relação às práticas inadequadas de conduta na produção do conhecimento científico. Método: a coleta de dados ocorreu por meio de pesquisa documental, correspondente às publicações de órgãos norteadores de pesquisas científicas, lançadas entre os anos de 2010 e 2017. Resultados: a análise dos dados gerou um quadro de Orientações de Conduta e as Organizações geradoras. As fontes observadas apresentaram documentações diversificadas e concordância, no que diz respeito ao termo má conduta científica. Conclusão: percebeu-se que é necessário esforço por parte das instituições, nas ações preventivas e pedagógicas em relação à produção científica, bem como a padronização das regras de avaliação e de punição em má conduta.

DESCRITORES: Ética; Direito autoral; Má conduta científica; Moral; Plágio.

\section{ETHICS AND INTEGRITY: CODE OF CONDUCT FOR SCIENTIFIC RESEARCH IN BRAZIL}

Objective: To present an analysis of the legal mechanisms that guide scientific research in Brazil in ethics, integrity and its related aspects, regarding misconduct in the production of scientific knowledge. Method: Data was collected through documentary research of publications from regulatory agencies that set the standards for scientific research released in the 2010-2017 period. Results: Data analysis generated a chart of Guidelines of Conduct and the Institutions that generated the records. Despite the differences in the documents of the sources investigated, they all agreed on the term "research misconduct". Conclusion: The institutions should carry out preventive and pedagogical actions targeted to scientific research, as well as promote the standardization of the rules of evaluation and punishment of misconduct.

KEYWORDS: Ethics; Copyright; Research misconduct; Moral; Plagiarism.

\section{ÉTICA E INTEGRIDAD: CONDUCTAS PARA PRODUCCIONES CIENTÍFICAS EN BRASIL}

Objetivo: presentar un análisis de dispositivos legales que sean parámetros para investigaciones científicas en Brasil asociados a la ética, la integridad y sus aspectos, en lo que se refiere a prácticas inadecuadas de conducta en la producción del conocimiento científico. Método: se recogieron los datos por medio de investigación documental, correspondiente a las publicaciones de órganos rectores de investigaciones científicas, publicadas entre los años de 2010 y 2017. Resultados: el análisis de los datos generó un cuadro de Orientaciones de Conducta y las Organizaciones generadoras. Las fuentes observadas presentaron documentaciones diversificadas y concordancia acerca del término mala conducta científica. Conclusión: se percibe que es necesario esfuerzo de las instituciones, en las acciones preventivas y pedagógicas en lo que se refiere a la producción científica, así como la estandarización de las reglas de evaluación y de punición en mala conducta.

DESCRIPTORES: Ética; Derecho autoral; Mala conducta científica; Moral; Plagio.

\footnotetext{
${ }^{1}$ Graduada em Matemática pela Universidade Federal de Goiás. Aluna do mestrado em Gestão Organizacional da Universidade Federal de Goiás. Catalão, GO, Brasil.

${ }^{2}$ Enfermeira. Doutora em Enfermagem. Docente no Programa de mestrado em Gestão Organizacional da Universidade Federal de Goiás. Catalão, GO, Brasil.

${ }^{3}$ Graduada em Redes de Comunicação pelo Centro Federal de Educação Tecnológica do Estado de Goiás. Aluna do mestrado em Gestão Organizacional da Universidade Federal de Goiás. Catalão, GỎ, Brasil.

${ }^{4}$ Enfermeira. Doutora em Enfermagem. Docente no Programa de mestrado em Gestão Organizacional da Universidade Federal de Goiás. Catalão, GO, Brasil.

${ }^{5}$ Graduada em Administração pelo Centro de Ensino Superior de Catalão. Mestre em Gestão Organizacional pela Universidade Federal de Goiás. Catalão, GO, Brasil.

${ }^{6}$ Graduada em Administração pela Universidade Federal de Goiás. Aluna do mestrado em Gestão Organizacional da Universidade Federal de Goiás. Catalão, GO, Brasil.
}

Universidade Federal de Goiás.

Rua Gurupi, 126 - 75.702-19. Catalão, Goiás, Brasil.

E-mail: robertaellias@gmail.com 


\section{INTRODUÇÃO}

A Ética é formada por princípios como o respeito, a justiça e a beneficência, que permeiam a reflexão sobre a moralidade e a atitude. Esse conjunto de princípios apresenta normas, que regulam a conduta e garantem o bem-estar do indivíduo na sociedade ${ }^{(1)}$. Já o termo Integridade de pesquisa refere-se aos deveres éticos, que os cientistas devem praticar ao realizarem pesquisas científicas ${ }^{(2)}$.

Desde 1980, houve grande preocupação em relação à ética e à integridade nas pesquisas científicas, devido ao aumento de casos de fraudes nas instituições, com maior ênfase nos Estados Unidos ${ }^{(3)}$. No Brasil, a preocupação relacionada ao assunto é fato recente. Para um aprimoramento sobre a discussão em questão, congressos vêm sendo promovidos, como o Brazilian Meeting on Research Integrity, Science and Publication Ethics - Brispe (I Brispe, 2010; II Brispe, 2012; III Brispe, 2014; IV Brispe, 2016).

Esses eventos têm por objetivo abordar as principais práticas na condução de uma pesquisa científica e estimular o envolvimento das instituições do país. O Brasil sediou também a $4^{\text {th }}$ World Conference on Research Integrity (WCRI) no ano de 2015, apoiado por organizações como CAPES (Comissão de Aperfeiçoamento de Pessoal do Nível Superior), CNPq (Centro Nacional de Desenvolvimento Científico e Tecnológico), FAPESP (Fundação de Amparo à Pesquisa do Estado de São Paulo) e a Academia Brasileira de Ciências.

A escolha do tema ética e integridade nas pesquisas científicas deu-se pela busca de uma melhor compreensão sobre essa discussão. O objetivo desse estudo é apresentar os dispositivos legais, que norteiam as pesquisas científicas no Brasil, no âmbito da ética e da integridade. Além disso, serão analisados os aspectos em relação às práticas inadequadas de conduta na produção do conhecimento científico.

Moral e ética são dois termos bastante utilizados na linguagem cotidiana e muitas vezes interpretados de forma errônea. Isso acontece porque ambas estão diretamente ligadas aos valores, como o certo e o errado. Enquanto a ética está relacionada à discussão de valores, responsabilidade e consciência, a moral refere-se à maneira de viver do indivíduo. Dessa forma, tem-se que a moral é um conjunto de regras de conduta, admitidas por um grupo ou sociedade, que determina como deve ser o comportamento dos indivíduos. Paralelo a isso, tem-se a ética, que é a reflexão sobre os princípios que fundamentam a moral $^{(4)}$.

Situações envolvendo Moral e Ética acontecem a todo o momento, em todos os campos do conhecimento. O crescente desenvolvimento tecnológico faz com que tais situações ocorram com frequência no campo da pesquisa.

A questão dos desvios de conduta no meio acadêmico-científico é abordada por um modelo proposto, que explicita seus principais facilitadores ${ }^{(5)}$. Um exemplo é o desempenho institucional, pois o reconhecimento é realizado com base na produção científica. Ou seja, nas submissões e publicações do produto final, que fazem com que o aluno/autor seja submetido a um nível de cobrança exacerbada ${ }^{(5)}$.

Dentre as diversas situações negativas envolvendo moral e ética na pesquisa, podem-se citar alguns problemas éticos comuns. São eles: desvio de conduta acadêmica, fabricação de dados, falsificação de dados, plágio, autoplágio, direito de autoria e conflito de interesses ${ }^{(6)}$.

Diante disso, estes problemas éticos são definidos por alguns autores como:

- Desvio de conduta acadêmica: definido como desvio de conduta, é a ação que objetiva fazer com que o falso seja visto como verdadeiro ${ }^{(6)}$. Tal termo pode ser usado para referir-se à fabricação, plágio e outras práticas repudiadas pela comunidade científica.

- Fabricação de dados e Falsificação de dados: a fabricação de dados em pesquisa é classificada como dados que são inventados ou falsificados e informações que são deliberadamente alteradas ${ }^{(7)}$.

- Plágio: o Guia de Recomendações de Práticas Responsáveis da Academia Brasileira de Ciências ${ }^{(8)}$ define como plágio a ação de apropriação de ideias ou trabalhos de terceiros, sem o devido crédito. 
- Autoplágio: acontece quando o pesquisador recicla seu texto já publicado anteriormente. Embora não seja configurado roubo de ideias, vários periódicos e revistas pedem a confirmação de que aqueles dados não foram publicados anteriormente ${ }^{(9)}$.

- Direito de autoria: o direito autoral se refere a um conjunto de prerrogativas de ordem patrimonial, atribuído ao autor sobre sua obra, sendo ela de origem literária, artística ou científica ${ }^{(10)}$.

- Conflito de interesses: é a incompatibilidade entre interesses pessoais e as obrigações de um indivíduo. Os autores exemplificam o conflito de interesses na medicina, quando o bem estar de um paciente pode ser prejudicado por interesses secundários como, por exemplo, ganho financeiro ${ }^{(11)}$.

Tais problemas éticos não são cometidos apenas por autores, mas também por editoras, revisores de revistas e periódicos ${ }^{(12)}$. Diante da discussão voltada à prática científica, torna-se necessário entender o conceito de ética e integridade nas pesquisas científicas. Desse modo, ética é o termo usado como referência sobre as questões morais, que determinarão a boa e a má conduta de uma sociedade. A ética também estabelece limites para a moral dessa mesma sociedade.

Com isso, a integridade na pesquisa só existe quando se consegue colocar em prática as normas éticas exigidas nas publicações científicas. A integridade na pesquisa está fundamentada em alguns princípios éticos como confiança, honestidade, beneficência, respeito, justiça e responsabilidade ${ }^{(13)}$.

A associação da integridade à pesquisa científica está no fato da ética ser a base da própria integridade. A ética é formada por um conjunto de princípios, que estabelece um padrão de conduta e orienta o comportamento do indivíduo em suas atitudes. A integridade na pesquisa científica tem como objetivo garantir que as práticas éticas, como honestidade, prudência e reconhecimento de igualdade, sejam adotadas pelos pesquisadores dentro das instituições. Com isso, espera-se reduzir os problemas associados à má conduta na pesquisa como plágio, fabricação ou falsificação de dados, entre outros ${ }^{(3)}$. A importância de disseminar a integridade e a ética nas pesquisas científicas está na apresentação de dispositivos legais, que possam nortear pesquisas científicas no Brasil, em relação a práticas inadequadas de conduta na produção do conhecimento científico.

\section{- MÉTODO}

Este estudo é uma Pesquisa exploratória, que utiliza como método a pesquisa documental em arquivos escritos e públicos ${ }^{(14)}$, disponíveis na base de dados do Portal de Periódicos, da Coordenação de Aperfeiçoamento de Pessoal de Nível Superior (CAPES). Esse portal reúne 128 bases referenciais, além de livros, enciclopédias, normas técnicas dentre outros. A dificuldade de acesso a publicações acadêmicas internacionais pelas bibliotecas brasileiras fez com que o Portal fosse criado.

A coleta de dados foi realizada no primeiro semestre de 2017, simultaneamente por dois pesquisadores independentes. Foram utilizadas as seguintes Strings: Ética e Integridade Científica, com um retorno de 122 publicações.

À luz de uma perspectiva histórica, a análise documental correspondeu às publicações de órgãos norteadores de pesquisas científicas, no período de 2010 a 2017. Para fortalecer o trabalho analítico, objeto central de interesse para inclusão, foram selecionados arquivos que retratassem normas direcionadas à integridade ética nas pesquisas, excluindo toda publicação que não fosse condizente com o tipo de documento.

Na segunda etapa, a fase de organização do material após a leitura, verificou-se o conjunto de documentos de forma sintética e a relevância para o objetivo proposto pelos pesquisadores. A partir dos cinco documentos selecionados, foi criada uma ficha de leitura individual, contendo resumo, referência bibliográfica da publicação e algumas transcrições de trechos, que poderiam ser utilizados posteriormente por cada pesquisador. Deste trabalho resultou um quadro de Orientações de Conduta e as Organizações Geradoras. 


\section{RESUlTADOS}

Regras e conceitos para estimular boas práticas em pesquisas científicas têm sido adotados por organizações governamentais. Essas instituições priorizam o desenvolvimento e a divulgação de regras de conduta, em virtude do crescimento do exercício impróprio da ética e da falta de integridade. Diante disso, foram encontradas as Orientações de Conduta nos cinco documentos selecionados nos critérios de inclusão e apresentadas no Quadro 1.

Quadro1 - Orientações de Conduta. Catalão, GO, Brasil, 2017.

\begin{tabular}{|c|c|c|}
\hline Documentos & Orientações de Conduta & Organizações \\
\hline $\begin{array}{l}\text { Relatório da } \\
\text { Comissão de } \\
\text { Integridade } \\
\text { de Pesquisa } \\
\text { Síntese }\end{array}$ & $\begin{array}{l}\text { Aborda a necessidade de boas práticas na pesquisa, como a verdade e a idoneidade. } \\
\text { Resultados falsos prejudicam o avanço do conhecimento no Brasil, além de resultar } \\
\text { em consequências econômicas e sociais. Possui duas linhas de ação: as ações } \\
\text { preventivas e pedagógicas. Outras medidas tomadas são de desestímulo à má } \\
\text { conduta, inclusive com a aplicação de punições. } \\
\text { Em 2011, foram estipuladas suas "Diretrizes Básicas para a Integridade Científica", } \\
\text { relacionadas aos direitos autorais e à proteção intelectual das ideias, como forma de } \\
\text { prevenção à falsificação e ao plágio nas pesquisas científicas }{ }^{(15)} \text {. }\end{array}$ & $\begin{array}{l}\text { CNPq - Centro } \\
\text { Nacional de } \\
\text { Desenvolvimento } \\
\text { Científico e } \\
\text { Tecnológico }\end{array}$ \\
\hline $\begin{array}{c}\text { Orientações } \\
\text { de Combate } \\
\text { ao plágio }\end{array}$ & $\begin{array}{l}\text { Políticas sobre propriedade intelectual por parte das instituições públicas ou } \\
\text { privadas, apoiadas por recomendações do Conselho Federal da Ordem dos } \\
\text { Advogados do Brasil (OAB). A recomendação reforça que a apropriação indevida } \\
\text { de conteúdo de terceiros pode causar perdas imensuráveis e que a facilidade de } \\
\text { acesso à internet é motivo de grande preocupação, no sentido da prática indevida } \\
\text { de cópias de textos. A OAB aconselha a utilização de softwares antiplágio, mas } \\
\text { ressalta que deve haver uma comissão para análise dos resultados }{ }^{(16)} \text {. }\end{array}$ & $\begin{array}{c}\text { CAPES - } \\
\text { Comissão de } \\
\text { Aperfeiçoamento } \\
\text { de Pessoal do } \\
\text { Nível Superior }\end{array}$ \\
\hline $\begin{array}{c}\text { Código de } \\
\text { Boas Práticas } \\
\text { Científicas }\end{array}$ & $\begin{array}{l}\text { Valores absolutos de honestidade, objetividade, veracidade, justiça e } \\
\text { responsabilidade devem ser inerentes à formação do perfil profissional, assim como } \\
\text { são considerados fiéis e verdadeiros os resultados de suas atividades científicas }{ }^{(17)} \text {. } \\
\text { Após a publicação, todas as informações levantadas na pesquisa devem ser } \\
\text { registradas e guardadas por tempo apreciável. Esse procedimento é a garantia de } \\
\text { que outros pesquisadores tenham acesso livre a esse material, além de assegurar } \\
\text { que todas as inquietações levantadas tenham respostas em tempo oportuno }{ }^{(17)} \text {. } \\
\text { A colaboração por parte do pesquisador em caso de investigação é imprescindível } \\
\text { e a falsa informação configura má conduta científica }{ }^{(17)} \text {. }\end{array}$ & $\begin{array}{c}\text { FAPESP - } \\
\text { Fundação } \\
\text { de Amparo à } \\
\text { Pesquisa do } \\
\text { Estado de São } \\
\text { Paulo }\end{array}$ \\
\hline $\begin{array}{c}\text { Resolução } n^{\circ} \\
466, \text { de } 12 \\
\text { de dezembro } \\
\text { de } 2012 .\end{array}$ & $\begin{array}{l}\text { Esclarece termos que geram dúvidas no momento da realização da pesquisa com } \\
\text { seres humanos e fundamenta a ética científica, que deve permear esses estudos }{ }^{(18)} \text {. } \\
\text { A análise ética da pesquisa primeiramente é encaminhada ao Comitê de Ética } \\
\text { em Pesquisa - CEP, a quem compete analisar e emitir parecer, após enviar os } \\
\text { protocolos de competência da Comissão Nacional de Ética em Pesquisa (CONEP) } \\
\text { (18). } \\
\text { O pesquisador deverá elaborar o Termo de Consentimento de Livre e Esclarecido } \\
\text { (TCLE) e manter toda espécie de arquivo gerado pela pesquisa sob sua guarda, } \\
\text { durante o período mínimo de cinco anos. }\end{array}$ & $\begin{array}{l}\text { Conselho } \\
\text { Nacional de } \\
\text { Saúde }\end{array}$ \\
\hline $\begin{array}{c}\text { Rigor e } \\
\text { Integridade } \\
\text { na } \\
\text { Condução } \\
\text { da Pesquisa } \\
\text { Científica }\end{array}$ & $\begin{array}{l}\text { As violações decorrentes de má-fé ou negligência nos princípios da integridade } \\
\text { científica podem se apresentar das seguintes formas: fabricação de resultados } \\
\text { e registros como se fossem reais, falsificação, plágio e autoplágio }{ }^{(8)} \text {. As } \\
\text { consequências da punição devem ser proporcionais à infração cometida, levando } \\
\text { em consideração a finalidade do ato e o intuito de tal ação. Enfatiza-se que entre o } \\
\text { que, de fato, é permitido e proibido há uma lacuna de entendimento e as decisões } \\
\text { constantemente não são claras, tornando as avaliações subjetivas. } \\
\text { De forma sucinta, apresenta as boas práticas na condução da pesquisa, assim como } \\
\text { premissas, princípios, boas e más condutas científicas. A responsabilidade principal } \\
\text { pela investigação de suspeita de má conduta é das instituições, que devem dispor } \\
\text { de comitês específicos para essa finalidade }{ }^{(8)} \text {. }\end{array}$ & $\begin{array}{c}\text { Academia } \\
\text { Brasileira de } \\
\text { Ciências }\end{array}$ \\
\hline
\end{tabular}




\section{DISCUSSÃO}

O desenvolvimento de boas práticas advém da formação do cientista, que deve estar pautada no discernimento do que é uma prática científica adequada ou imprópria. Para a formação completa do cientista, ele deve possuir habilidades técnicas, conhecimento geral em outras áreas, que não sejam de sua especialidade, além de um perfil de boas práticas. Esse último é primordial para a excelência profissional ${ }^{(19)}$.

Os princípios de integridade científica - honestidade, objetividade, veracidade, justiça e responsabilidade - apresentados em todos os documentos analisados, enfatizam que o perfil profissional do pesquisador deve ser construído sob estes fundamentos, desde os primeiros passos rumo a sua jornada de pesquisador. Além disso, esses princípios devem ser inerentes ao contorno da instituição que se propõe a realizar pesquisa ${ }^{(8,15-17)}$.

As fontes pesquisadas identificam documentações diversificadas quanto à forma de apresentação. São elas relatório, manual, resoluções e orientações. Não há um formato padronizado, para que os dados que compõem as orientações de pesquisa no Brasil sejam apresentados.

Em geral, verifica-se que há concordância nas fontes pesquisadas, no que diz respeito ao termo má conduta científica. Por unanimidade na gravidade, são descritas a falsificação, a fabricação e o plágio. Esses desvios são especificados de forma clara e concisa, para que o pesquisador e a instituição não realizem equívocos, sobre o que considerar má conduta ${ }^{(8,15-17)}$. É de comum acordo entre as fontes, que o mau comportamento na pesquisa gera prejuízos de cunho financeiro, moral e descrédito à sociedade.

O CNPq é um órgão ligado ao Ministério da Ciência, Tecnologia e Inovação do Brasil e um incentivador e financiador da pesquisa cientifica no país, em várias áreas do conhecimento ${ }^{(15)}$. Para o CNPq, a fabricação e a falsificação de dados, o plágio e o autoplágio devem ser coibidos, por meio de mecanismos que identifiquem as práticas de fraudes. Igualmente, é de grande importância para a instituição incentivar a ética e a integridade na pesquisa ${ }^{(15)}$. Observou-se, ainda, que a Proteção Intelectual de Ideias foi abordada com maior ênfase pelo $\mathrm{CNPq}$, como forma de prevenção da má conduta na pesquisa ${ }^{(15)}$.

A FAPESP e a Resolução do CNS no 466/12 abordam o conflito potencial de interesse na pesquisa(17-18) . Essa Resolução descreve sua natureza de forma detalhada, elucidando à instituição de pesquisa e ao pesquisador quando há medidas necessárias a serem tomadas, no caso de conflito de interesses no meio do processo de pesquisa ${ }^{(18)}$, e quais seriam elas. Estes documentos também enfatizam a importância da guarda das informações e registros gerados pela pesquisa, tanto pelo pesquisador quanto pelo CEP. A Resolução determina o tempo mínimo necessário de cinco anos para a guarda desses documentos ${ }^{(18)}$.

Por serem responsáveis pela promoção da integridade e da ética na pesquisa, as instituições têm uma parcela de responsabilidade na produção científica. É sua função difundir claramente as regras, políticas e procedimentos referentes às práticas adotadas nas pesquisas. É necessária a adoção de um instrumento próprio de verificação pela instituição, pois, em caso de ocorrência ou investigação de má conduta, ela deverá ser comunicada imediatamente e os procedimentos a serem adotados devem ser de clara interpretação ${ }^{(17)}$.

A orientação é para que toda instituição de pesquisa, seja ela pública ou privada, disponibilize à comunidade acadêmica as disposições gerais, que norteiam o processo de realização de pesquisa. A instituição deve, ainda, deixar todas as etapas explícitas, inclusive a questão da investigação, em caso de má conduta na pesquisa. Havendo confirmação da má conduta, os critérios de punição, as consequências e medidas a serem tomadas devem estar claramente explícitos. Essas medidas ${ }^{(15)}$ são de responsabilidade da instituição de pesquisa.

Não foi possível encontrar o limite da aplicação da forma preventiva da prática de má conduta científica. As fontes apresentam a educação e a informação às comunidades acadêmicas como medidas preventivas, mas o conceito foi apresentado de forma ampla. Não se obteve, no entanto, evidências de sua aplicabilidade. 


\section{CONSIDERAÇÕES FINAIS}

Diante do que foi proposto, entende-se que o objetivo foi alcançado e que foram apresentados dispositivos legais, que norteiam a pesquisa científica no Brasil. A subjetividade nas disposições analisadas foi a dificuldade encontrada durante a realização do trabalho.

Entende-se que a promoção da discussão sobre as questões de integridade e ética em pesquisa é de grande valor, para o crescimento da prevenção da má conduta na pesquisa. É de grande importância também que esta discussão perpasse os portões das instituições e universidades, envolvendo a sociedade. O objetivo é avançar sobre definições mais assertivas e claras sobre prevenção, coibição e punição da prática de má conduta em pesquisas. A não comunicação por pesquisadores ou instituições, quando se observa qualquer má conduta na pesquisa, é um obstáculo para que as fontes pesquisadas tomem medidas necessárias para coibir essa prática.

Foi possível observar que no Brasil a preocupação com o tema integridade e ética em pesquisa é recente, começando com discussões a respeito a partir de meados da década de 1980. Para manter o tema em constante evolução, foram realizados congressos como IV BRISPE (2016) e a $4^{\text {th }}$ World Conference on Research Integrity (WCRI) no ano de 2015. Porém, ainda há muito a galgar no processo de realização de pesquisas com integridade e ética.

Vários pontos observados na análise das fontes, como a criação do CEP em todas as instituições que realizam pesquisa, são passos positivos rumo ao avanço da construção deste processo. É importante que os órgãos de fomento de pesquisa passem a utilizar o CEP, como critério para colaboração na realização e publicação da pesquisa. A punição cabível da má conduta científica muitas vezes não está disponível na esfera das instituições, fazendo-se necessário o apoio da área cível, para que tais práticas sejam coibidas.

Sugere-se que pesquisas futuras sejam realizadas em diversas áreas do conhecimento, sobre o tema integridade e ética na pesquisa, com análises de técnicas estatísticas. Indica-se também a utilização da pesquisa qualitativa, por se tratar de conceitos que (ainda) não possuem um consenso em toda sociedade acadêmica. Por fim, sugere-se incluir o assunto no currículo acadêmico, para abordar o tema com especificidade em todas as áreas de conhecimento. Esse, certamente, seria um diferencial para que a má conduta na pesquisa não continue a ocorrer.

\section{REFERÊNCIAS}

1. El-Guindy MM. Metodologia e ética na pesquisa científica. São Paulo: Santos; 2004.

2. Fundação de Amparo à Pesquisa do Estado de São Paulo (FAPESP). Sobre a integridade ética da pesquisa. [Internet] São Paulo: FAPESP; 2011 [acesso em 25 mar 2016]. Disponível: http://www.fapesp.br/6566.

3. Russo M. Ética e integridade na ciência: da responsabilidade do cientista à responsabilidade coletiva. Estud. av. [Internet] 2014;28(80) [acesso em 25 mar 2016]. Disponível: http://dx.doi.org/10.1590/S0103-40142014000100016.

4. Nosella P. Ética e pesquisa. Educ. Soc. [Internet] 2008;29(102) [acesso em 25 mar 2016]. Disponível: http://dx.doi. org/10.1590/S0101-73302008000100013.

5. Yokomizo CA. Desvios de conduta na pesquisa acadêmico-científica. In: XXXII Encontro Nacional Associação Nacional de Pós-Graduação e Pesquisa em Administração (ENANPAD). Rio de Janeiro: ANPAD; 2008.

6. Coury HJCG. Research and scientific publication integrity. Rev. bras. fisioter. [Internet] 2012;16(1) [acesso em 12 abr 2016]. Disponível: http://dx.doi.org/10.1590/S1413-35552012000100001.

7. Hossne WS, Vieira S. Fraude em ciência: onde estamos? Rev. bioet. [Internet] 2007;15(1) [acesso em 25 mar 2016 ]. Disponível: http://revistabioetica.cfm.org.br/index.php/revista_bioetica/article/view/29. 
8. Academia Brasileira de Ciências. Rigor e Integridade na Condução da Pesquisa Científica. Guia de Recomendação de Práticas Responsáveis. [Internet] Rio de Janeiro: Academia Brasileira de Ciências; 2013 [acesso em 23 mar 2016]. Disponível: http://www.abc.org.br/IMG/pdf/doc-4311.pdf.

9. Panter M. Em suas próprias palavras: Melhores práticas para evitar o plágio. [Internet] AJE; 2015 [acesso em 12 abr 2016]. Disponível: https://www.aje.com/br/arc/dist/docs/AJE-em-suas-proprias-palavras.pdf.

10. Araya ERM, Vidotti SABG. Criação, proteção e uso legal de informação em ambientes da World Wide Web. São Paulo: UNESP; 2010.

11. Alves EMO, Tubino P. Conflito de interesses em pesquisa clínica. Acta Cir. Bras. 2007;22(5) [acesso em 25 mar 2016]. Disponível: http://dx.doi.org/10.1590/S0102-86502007000500015.

12. Vázquez SC, Vilà MAV. Ética em lãs publicaciones científicas. Rev de La Facultad de Ciencias de La Salud. [Internet] 2006;4 [acesso em 25 mar 2016]. Disponível: https://revistas.uax.es/index.php/biociencia/article/view/652/608.

13. Instituto Bioética, Phitan LH, Oliveira AP. Ética e integridade na pesquisa: o plágio nas publicações científicas. Rev. AMRIGS. [Internet] 2013;57(3) [acesso em 12 abr 2016]. Disponível: http://www.amrigs.com.br/revista/57-03/1250.pdf.

14. Lakatos EM. Marconi MA. Fundamentos de Metodologia Científica. São Paulo: Atlas; 2017.

15. Centro Nacional De Desenvolvimento Científico e Tecnológico (CNPq). Relatório da Comissão de Integridade de Pesquisa do CNPq. [Internet] Brasília: Centro Nacional De Desenvolvimento Científico e Tecnológico; 2011 [acesso em 28 mar 2016]. Disponível: http://cnpq.br/documents/10157/a8927840-2b8f-43b9-8962-5a2ccfa74dda.

16. Coordenação De Aperfeiçoamento De Pessoal De Nível Superior (CAPES). Orientações Capes - Combate ao plágio. [Internet] Brasília: CAPES; 2011 [acesso em: 25 mar 2016]. Disponível: https://www.capes.gov.br/images/stories/ download/diversos/OrientacoesCapes_CombateAoPlagio.pdf.

17. Fundação de Amparo À Pesquisa do Estado de São Paulo (FAPESP). Código de Boas Práticas Científicas. [Internet] São Paulo: FAPESP; 2014 [acesso em 25 mar 2016] Disponível: http://www.fapesp.br/boaspraticas/FAPESPCodigo_de_ Boas_Praticas_Cientificas_2014.pdf.

18. Ministério da Saúde (BR). Conselho Nacional de Saúde. Diretrizes e normas regulamentadoras de pesquisa envolvendo seres humanos. Resolução n. 466, de 12 de dezembro de 2012. Brasília; 2012.

19. Volpato GL. Ciência além da visibilidade: ciência, formação de cientistas e boas práticas. Botucatu: Best Writing; 2017. 